\title{
Building Stock and Building Typology of Kigali, Rwanda
}

\author{
Felix Bachofer 1,2,*(i), Andreas Braun 2으, Florian Adamietz ${ }^{2}$, Sally Murray ${ }^{3}$, Pablo d'Angelo ${ }^{1}$, \\ Edward Kyazze ${ }^{4}$, Abias Philippe Mumuhire ${ }^{5}$ and Jonathan Bower ${ }^{3}$ \\ 1 German Aerospace Center (DLR), Earth Observation Center (EOC), 82334 Wessling, Germany \\ 2 Department of Geosciences, University of Tuebingen, 72070 Tuebingen, Germany \\ 3 International Growth Centre (IGC), KG 12 Ave, Kigali 3004, Rwanda \\ 4 Ministry of Infrastructure (MININFRA), Urbanization and Human Settlements Division, KG 7 Ave, \\ Kigali 24, Rwanda \\ 5 City of Kigali, Urban Planning and Construction One Stop Center Unit, KN 3 Ave, Kigali 3527, Rwanda \\ * Correspondence: felix.bachofer@dlr.de; Tel.: +49-8153-28-3183
}

Received: 5 June 2019; Accepted: 19 July 2019; Published: 21 July 2019

check for updates

\begin{abstract}
This study uses very high-resolution Pléiades imagery for the densely built-up central part of the City of Kigali for the year 2015 in order to derive urban morphology data on building footprints, building archetypes and building heights. Aerial images of the study area from 2008-2009 were used in combination with the 2015 dataset to create a change monitoring dataset on a single building basis. A semi-automated approach was chosen which combined an object-based image analysis with an expert-based revision. The result is a geospatial dataset that detects 165,625 buildings for 2008-2009 and 211,458 for 2015. The dataset includes information on the type of changes between the two dates. Analysis of this geospatial dataset can be used for a range of research applications in economics and the social sciences, as well as a range of policy applications in urban planning and municipal finance administration.
\end{abstract}

Dataset: Available as supplementary file and available at Zenodo (DOI: 10.5281/zenodo.3239271)

Dataset License: CC-BY 4.0

Keywords: building inventory; building types; change detection; remote sensing; Kigali; Rwanda

\section{Summary}

Urban agglomerations in emerging countries in the Global South are experiencing rapid changes in their urban extent and morphology, due to the growth of population, rural-urban migration, and rising incomes. Access to updated information on the qualitative and quantitative status of settlements is relevant, in order to monitor and inform the housing sector, spatial and infrastructure planning, municipal revenue collection and budgeting, and the supply of social services. Very high-resolution (VHR) multispectral satellite images are one important, cost effective source of regular, updated, data on urban land use and built-up areas [1]. The authors acquired a Pléiades satellite image from August 2015 for the central part of the capital city of Rwanda, Kigali. Object-based image analysis (OBIA) and expert-based post-classification were then applied to derive building footprints and building heights and to assign every building to one of nine building archetypes. In a second step, building footprint data from aerial images of the same area in 2008-2009 were analyzed, to identify the change of the building stock in the respective period. In total, 165,625 built entities were detected for 2008-2009 and 211,458 for 2015; this entails a $27.7 \%$ increase in the number of buildings. The Government of Rwanda 
has expressed an interest in cost-effectively monitoring and managing the building supply in Kigali. Information from the geospatial dataset can be of use for various research and policy objectives in spatial planning, infrastructure planning, property valuation -which can help in municipal revenue collection and administration — and economic geography more broadly. Further analysis of the proposed dataset might also provide insights that can be transferred to cities with similar geographic and demographic settings. We anticipate that these data will have many other uses to improve our ability to understand dynamics of urban growth. In addition, the datasets can be valuable for the training and testing of image analysis and computer vision methods. The dataset presented is a revised version of a dataset that was used for a published report on the housing supply in Kigali [2].

\section{Methods}

A semi-automatic methodology was applied to a Pleaides satellite image of 2015 to derive building footprints and building archetypes. OBIA was used to delineate building geometries and to provide an initial classification of buildings into typologies. An elaborate post-processing and revision process was then applied. The 2015 dataset and aerial images of 2008-2009 were used to detect the change of the building stock for the respective period.

\subsection{Study Area}

Kigali is the capital city of Rwanda; it had a population of 1,132,686 in 2012 according to the most recent Census [3], but this population is growing rapidly. Hills and valleys characterize the topography of the city [4] and its morphology is heterogeneous. A new master plan for Kigali was released in 2013 and is currently being updated [5]. Building activities in the wetlands are restricted. The central business district (CBD) is located on an elevated plateau in the Nyarugenge sector (Figure 1, focus area). Unplanned settlements lie adjacent on slopes in the north, west and south; there are villas immediately to the east, followed by an old industrial area in the wetlands. New middle-income and high-income residential areas are emerging throughout the city. Unplanned settlements become more prevalent further from the CBD and sprawl into the rural areas of the city.

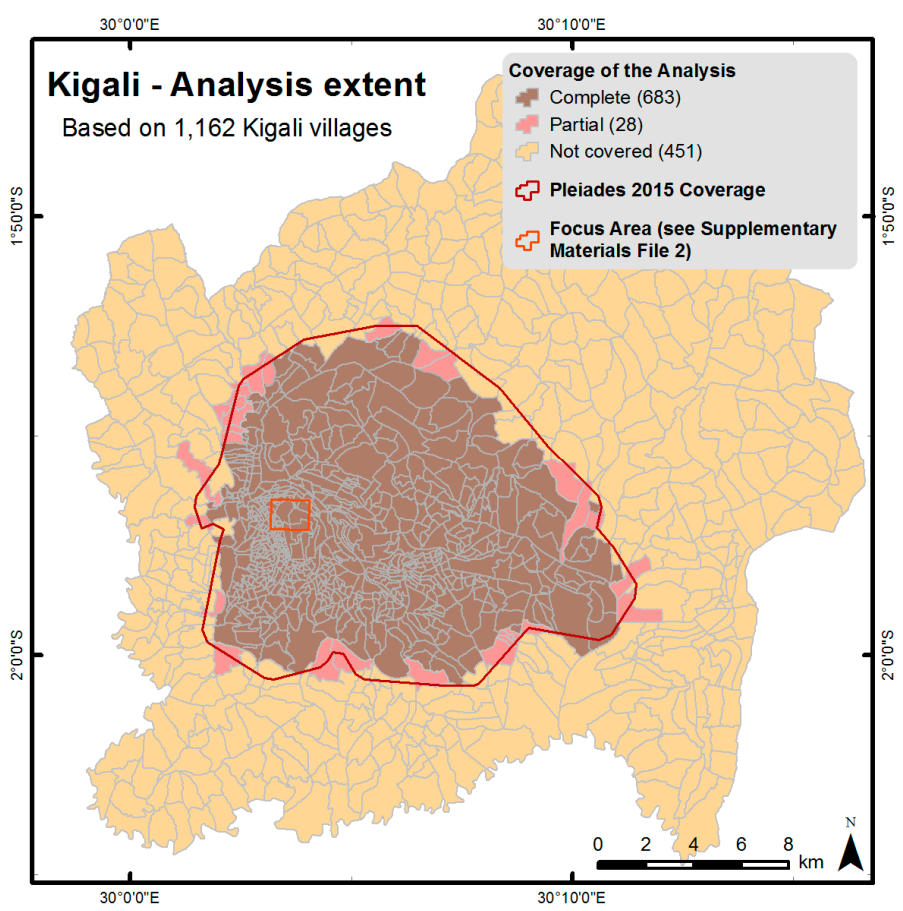

Figure 1. Study area and analysis extent. 


\subsection{Remote Sensing Data}

A Pléiades tri-stereoscopic satellite image (2015-08-09) was acquired for the densely built-up part of the city of Kigali (Figure 1). The two satellites of the Pléiades mission (1A and 1B) were launched in 2011 and 2012. The satellite constellation provides images with a spatial resolution of $70 \mathrm{~cm}$ for the panchromatic channel and $2.8 \mathrm{~m}$ for the 4 multispectral channels. The physical resolution is resampled to a spatial resolution of $50 \mathrm{~cm}$ and $2 \mathrm{~m}$ respectively [6]. For further processing, the multispectral information was pansharpened to the resolution of the panchromatic channel [7]. The Pleiades image was orthorectified using a digital surface model that was derived of the tri-stereoscopic image acquisition (see Section 2.7). The 2008-2009 dataset is the product of the last aerial photography mission that was conducted in 2008 and 2009 and which resulted in orthoimages covering Rwanda [8]. The spatial resolution of the images is $25 \mathrm{~cm}$. Only visual spectral bands (blue, green, and red) were taken, and the radiometric information of the images was adjusted with unknown parameters. This limits the possibilities of an automatic analysis of the 2008-2009 data.

\subsection{Reference Data}

To contribute to the image classification and the building extraction, as well as the validation of the results, reference information was collected for 889 buildings in three field surveys between 2014 and 2015. These reference data include information on the respective GPS position, reference pictures, building type, roof material, and roof type, as well as the building height for 837 of the reference buildings. Subsequent to the data collection, the measured GPS positions were assigned to the respective reference buildings identified in the remote sensing images by the surveyors, in order to correct for GPS measurement variances.

\subsection{Building Typology}

Based on an analysis of the reference data collected and discussions with local stakeholders, a series of building archetypes were defined that can be identified from remote sensing images (Table 1 , see detailed description in Supplementary Materials File1). They are based on the morphological characteristics of a building, not its functional usage. The minimum area of a building in the final dataset is $5 \mathrm{~m}^{2}$. Class-dependent thresholds are defined in Table 1. The short names defined in Table 1 are used to refer to the respective building class in this document.

Table 1. Building archetypes and properties.

\begin{tabular}{|c|c|c|c|c|c|c|}
\hline $\begin{array}{c}\text { Building } \\
\text { Archetypes/Building Class }\end{array}$ & Code & $\begin{array}{l}\text { Short } \\
\text { Names }\end{array}$ & $\begin{array}{l}\text { Minimum } \\
\text { Area }\left(\mathrm{m}^{2}\right)\end{array}$ & $\begin{array}{l}\text { Maximum } \\
\text { Area }\left(\mathrm{m}^{2}\right)\end{array}$ & $\begin{array}{l}\text { Minimum } \\
\text { Height (m) }\end{array}$ & $\begin{array}{l}\text { Maximum } \\
\text { Height (m) }\end{array}$ \\
\hline $\begin{array}{l}\text { Rudimentary, basic or } \\
\text { unplanned buildings }\end{array}$ & 1 & Basic & 5 & 150 & 2.1 & 6 \\
\hline $\begin{array}{l}\text { Building in block } \\
\text { structure/large } \\
\text { courtyard buildings }\end{array}$ & 2 & Block & 5 & - & 2.1 & 8 \\
\hline Bungalow-type buildings & 3 & Bungalow & 40 & 500 & 3.1 & 12 \\
\hline Villa-type buildings & 4 & Villa & 150 & 600 & 3.2 & 15 \\
\hline $\begin{array}{l}\text { Low to mid-rise multi-unit } \\
\text { buildings }\end{array}$ & 5 & Mid-rise & 100 & - & 3 & 10 \\
\hline High-rise buildings & 6 & High-rise & 200 & - & 8 & - \\
\hline Halls & 7 & Hall & 100 & - & 3 & - \\
\hline Special structures & 8 & Special & 5 & - & - & - \\
\hline Construction site & 9 & Construction & 5 & - & & \\
\hline
\end{tabular}




\subsection{Object-Based Image Analysis (OBIA)}

OBIA was chosen to classify land use and land cover (LULC) from the Pléiades image. With OBIA, a remote sensing image is subdivided into image segments consisting of neighboring pixels [9]. A multi-resolution segmentation approach was applied for the delineation of image objects $[10,11]$. In this bottom-up approach, region merging is applied starting from pixel level. The segmentation process was enhanced by an edge layer, derived with the Canny edge operator [12,13]. The resulting image segments were classified with a rule-based approach. The parameters used for the ruleset were the spectral information of the Pleiades image, the three first principle components and the Normalized Differenced Vegetation Index (NDVI). A thematic road layer (revised OpenStreetMap layer [14]) was used to delineate traffic infrastructure from building objects. Of the resulting LULC classification, only the class representing built-up objects was considered for further processing. Based on the building class thresholds (Table 1) and the segment properties, a preliminary classification of the building footprints was conducted.

\subsection{Geospatial Processing, Modelling, Expert Based Revision, and Manual Editing}

A multi-step post-processing of the rule-based OBIA was necessary in order to overcome some of the limitations of the dataset. In the intermediate dataset, large patches detected as a single building often in fact represented multiple adjacent buildings in densely built-up areas. The official cadastral dataset of Kigali from August 2014, which was provided by the City of Kigali, was used to split these large objects at the borders of plots.

However, for many plots, several adjacent "Basic" buildings remain, resulting in an underestimation of the number of "Basic" buildings. To give a better estimation of the total number of basic buildings, 1162 "Basic" buildings were digitized manually and assessed using various descriptive statistics. The median ground floor area is $75.2 \mathrm{~m}^{2}$. After a visual inspection of the results, as well as taking into account the statistics, the authors decided to split areas as soon as the doubled median size is reached $\left(150.4 \mathrm{~m}^{2}\right)$ and for "Basic" buildings above this size, to add a further split every $75.2 \mathrm{~m}^{2}$ using a look-up table (LUT, Table 2). Therefore, basic buildings with the respective attribute "Model $=1$ " (see Table 7), do not represent the real-world delineations to adjacent buildings.

Table 2. LUT to model the number of "Basic" buildings of large patches. The histogram is showing the distribution of the ground floor area of the manually digitized reference buildings.

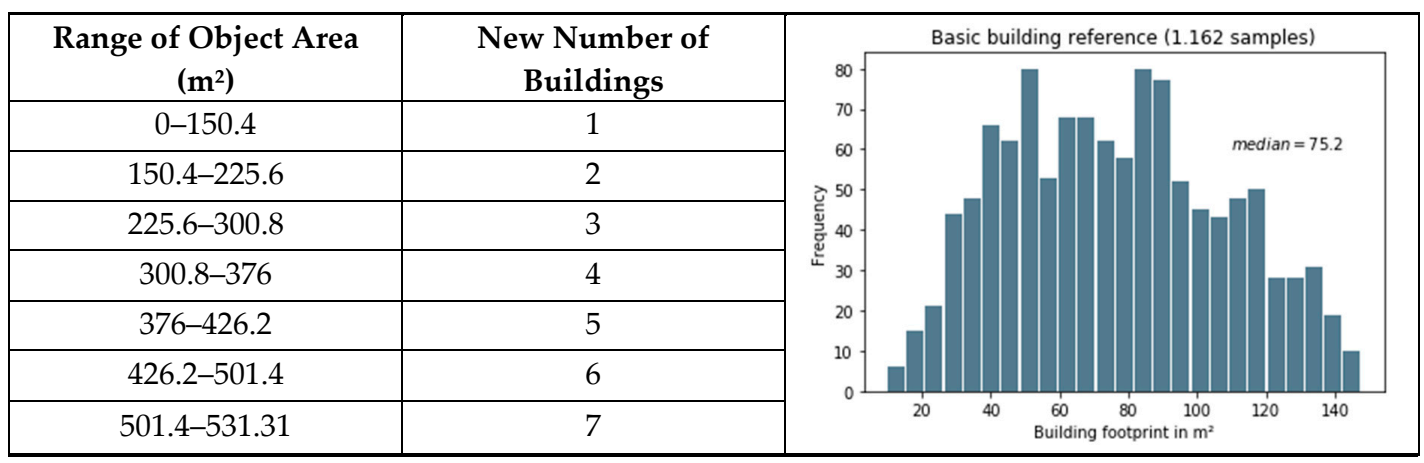

The building outlines detected with OBIA mostly occur as irregular shapes without straight edges, due to the spatial resolution of the Pléiades image and the segmentation process. In order to provide buildings with more standardized geometries for use in urban planning and cartographic illustrations, the outlines were automatically generalized to reduce geometric artifacts and to create more regular and angular shapes [15]. The Shape Index (SI) was utilized to identify and remove artefacts [16]. The dataset was also corrected for topology and plausibility. 
In some cases, the spectral properties of rusty corrugated metal roofs were similar to the surrounding open soil and dusty roads. The segmentation and classification in the OBIA processing was therefore erroneous. In addition, light and shadow effects of complex roof structures often resulted in several segments where one would have been correct. A laborious visual inspection of the intermediate results (object geometries and classification) was conducted and a manual correction applied where appropriate. A manual correction of the delineations and exact geometries of the modelled "Basic" buildings using the LUT was not applied.

A mapping of the change between the aerial images of 2008-2009 and the Pléiades 2015 analysis was then conducted manually. The reason for this is that the aerial images do not provide spectral information in the infrared domain, and color adjustments by the initial data provider lowered the radiometric resolution, resulting in the automated identification of buildings and type changes having insufficient accuracy. For the manual revision, the aerial images were overlaid with the 2015 results and then revised for the existence of buildings and the change of geometries. In addition, the type of change between the periods was also recorded in this process (see Table 3).

Table 3. Description of change types.

\begin{tabular}{cr}
\hline $\begin{array}{c}\text { Change Code } \\
1\end{array}$ & Type of Change \\
\hline 2 & $\begin{array}{r}\text { No change } \\
\text { Npgrading/ renovation (roof, structure) of an existing building or newly built building } \\
\text { without a significant change of the building class or footprint area }\end{array}$ \\
\hline 4 & $\begin{array}{r}\text { Upgrading/ renovation (roof, structure) of an existing building or newly built building } \\
\text { with a change of the building class. No change in the number of buildings and the } \\
\text { footprint area }\end{array}$ \\
\hline 5 & $\begin{array}{r}\text { Building replaced by one or more newly built buildings with a change of the building } \\
\text { class OR a significant change of the footprint area }\end{array}$ \\
\hline 6 & Building demolished
\end{tabular}

\subsection{Building Heights}

A Digital Surface Model (DSM) was derived from the tri-stereoscopic Pléiades data using the approach described in [17]. As dense matching requires a relative orientation at sub-pixel level, bundle block adjustment was used estimate RPC (rational polynomial coefficient) bias corrections for each Pleiades image. Pairwise dense image matching was performed using Semi-Global Matching (SGM), producing a point cloud for each of the three stereo pairs. The point clouds were reprojected into a digital surface model with a grid spacing of $0.5 \mathrm{~m}$ and merged using pixel-wise median. After removing small, inconsistent regions, remaining no-data areas caused by occlusions and dark shadows were filled by propagating the ground height. A digital terrain model (DTM) was generated from the DSM using an adapted version of the method reported in [18], which analyzes height steps and slopes along multi-directional trajectories at each DSM pixel. Holes in the DTM were closed using interpolation, and a normalized DSM (nDSM) was generated for obtaining relative heights (DSM minus DTM).

It was straightforward to determine building heights for objects in flat areas (such as the CBD). For other areas, Kigali's concave and convex slopes, as well as high building density in some areas, presented a challenging setting for stereoscopic analyses and resulted in positive and negative variances. A building class-dependent approach was chosen to assign building heights to the respective footprints of 2015. The mean value of the nDSM of each object was derived, which had lower deviations than the median or maximum value. In case the value exceeded the minimum or maximum threshold of the reference data (see Table 1), the height of the building was assigned to the respective threshold. 


\section{Data Description}

\subsection{Basic Statistics on the Dataset}

Table 4 illustrates the basic statistics of the resulting spatial datasets. The "Basic" building type is predominant; the area of buildings of this type increased by 20.5\% between 2008-2009 and 2015. However, the number of higher value type buildings such as "Bungalow" and "Villa" increased by a higher percentage. The number of construction sites that could be identified from remote sensing dropped by $58.5 \%$. The total number of buildings, as well as the total built-up area in the study area, increased by $27.7 \%$ and $27.8 \%$ respectively. Exemplary illustrations of the building typology for the CBD of Kigali are provided in Supplementary Materials File2.

Table 4. Basic results derived from the dataset.

\begin{tabular}{|c|c|c|c|c|c|c|c|c|}
\hline $\begin{array}{l}\text { Building } \\
\text { Type }\end{array}$ & $\begin{array}{l}\text { No. of } \\
\text { Buildings } \\
2008-2009\end{array}$ & $\begin{array}{l}\text { No. of } \\
\text { Buildings } \\
2015\end{array}$ & $\begin{array}{l}\text { Change of } \\
\text { Number of } \\
\text { Buildings }\end{array}$ & $\begin{array}{c}\text { Change } \\
\text { in } \%\end{array}$ & $\begin{array}{l}\text { Area of Buildings } \\
2008-2009\left(\mathrm{~m}^{2}\right)\end{array}$ & $\begin{array}{l}\text { Area of } \\
\text { Buildings } \\
2015\left(\mathrm{~m}^{2}\right)\end{array}$ & $\begin{array}{c}\text { Total Area } \\
\text { Change }\left(\mathrm{m}^{2}\right)\end{array}$ & $\begin{array}{c}\text { Area } \\
\text { Change } \\
\text { in } \%\end{array}$ \\
\hline Basic & 135,577 & 170,805 & 35,228 & $26.0 \%$ & $9,590,293$ & $11,558,170$ & $1,967,877$ & $20.5 \%$ \\
\hline Block & 1609 & 1587 & -22 & $-1.4 \%$ & 339,830 & 340,747 & 917 & $0.3 \%$ \\
\hline Bungalow & 20,313 & 27,610 & 7297 & $35.9 \%$ & $3,853,114$ & $5,179,569$ & $1,326,455$ & $34.4 \%$ \\
\hline Villa & 1542 & 4781 & 3239 & $210.1 \%$ & 471,511 & $1,371,557$ & 900,046 & $190.9 \%$ \\
\hline Mid-rise & 503 & 806 & 303 & $60.2 \%$ & 290,089 & 470,566 & 180,477 & $62.2 \%$ \\
\hline High-rise & 211 & 371 & 160 & $75.8 \%$ & 154,731 & 303,134 & 148,403 & $95.9 \%$ \\
\hline Hall & 3396 & 4306 & 910 & $26.8 \%$ & $1,896,004$ & $2,456,091$ & 560,087 & $29.5 \%$ \\
\hline Special & 211 & 253 & 42 & $19.9 \%$ & 48,338 & 61,508 & 13,170 & $27.2 \%$ \\
\hline Construction & 2263 & 939 & -1324 & $-58.5 \%$ & 611,744 & 311,927 & $-299,817$ & $-49.0 \%$ \\
\hline SUM & 165,625 & 211,458 & 45,833 & $27.7 \%$ & $17,255,654$ & $22,053,269$ & $4,797,615$ & $27.8 \%$ \\
\hline
\end{tabular}

\subsection{Accuracy Assessment and Known Limitations}

As explained in the Methods section, the number and the geometries of a large proportion of "Basic" buildings is the result of a modelling approach based on the statistics of manually digitized building footprints. The geometries of all buildings result from the combination of OBIA segments, automatic generalization, and eventual manual revision or complete manual digitizing. The geometries are therefore only an approximation of the real-world building footprints.

Using the reference information of the field campaigns, an accuracy assessment of the building type classification of 2015 was applied. It shows that, on the one hand, a high overall accuracy could be achieved, but on the other hand, even with an extensive manual revision of the dataset, there are differences between on-the-ground validation and remote sensing image interpretation (Table 5).

Table 5. Accuracy assessment of the building type classification 2015. No information on construction sites (class 9) was collected for the reference data.

\begin{tabular}{|c|c|c|c|c|c|c|c|c|c|c|}
\hline & & \multicolumn{8}{|c|}{ Classified Building Types } & \multirow{2}{*}{ Producer's Accuracy } \\
\hline & & 1 & 2 & 3 & 4 & 5 & 6 & 7 & 8 & \\
\hline \multirow{8}{*}{ 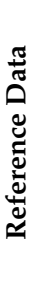 } & 1 & 330 & 1 & 3 & 0 & 0 & 0 & 0 & 0 & $99 \%$ \\
\hline & 2 & 0 & 84 & 0 & 0 & 0 & 0 & 0 & 0 & $100 \%$ \\
\hline & 3 & 11 & 0 & 243 & 2 & 0 & 0 & 1 & 0 & $95 \%$ \\
\hline & 4 & 0 & 0 & 11 & 90 & 0 & 0 & 0 & 0 & $89 \%$ \\
\hline & 5 & 0 & 0 & 1 & 0 & 24 & 2 & 2 & 0 & $83 \%$ \\
\hline & 6 & 0 & 0 & 0 & 0 & 1 & 37 & 0 & 0 & $97 \%$ \\
\hline & 7 & 1 & 0 & 2 & 0 & 1 & 0 & 38 & 0 & $90 \%$ \\
\hline & 8 & 0 & 1 & 1 & 0 & 0 & 0 & 0 & 2 & $50 \%$ \\
\hline \multicolumn{2}{|c|}{$\begin{array}{l}\text { User's } \\
\text { Accuracy }\end{array}$} & $96 \%$ & $98 \%$ & $93 \%$ & $98 \%$ & $92 \%$ & $95 \%$ & $93 \%$ & $100 \%$ & $\begin{array}{c}\text { Overall Accuracy } \\
848 / 889=95.4 \%\end{array}$ \\
\hline
\end{tabular}

An accuracy assessment was also conducted for the adjusted building heights (in the knowledge that the heights were adjusted by thresholds derived of the reference dataset). The analysis gives some background on the derivations that have to be expected with the dataset (Table 6). 
Table 6. Accuracy of building heights of 2015 using 837 reference values.

\begin{tabular}{cccccccccc}
\hline Building Type & $\mathbf{1}$ & $\mathbf{2}$ & $\mathbf{3}$ & $\mathbf{4}$ & $\mathbf{5}$ & $\mathbf{6}$ & $\mathbf{7}$ & $\mathbf{8}$ & All Buildings \\
\hline Mean absolute derivation in $\mathrm{m}$ & 0.78 & 0.83 & 0.84 & 1.28 & 3.83 & 5.11 & 1.54 & 4.23 & 1.21 \\
\hline
\end{tabular}

\subsection{Private Data Protection}

The dataset does not contain any non-anonymous data collected during the field reference campaigns. The attributes are purely a result of the geospatial analyses described in the Methods section. A precise cadastral dataset was used to intersect and split large buildings situated on more than one parcel. However, the data user cannot be certain of the original plot geometries since subsequent automatic generalisation of the building geometries altered the extent and outlines of the building footprints.

\subsection{Data Type}

The spatial dataset named EO4Kigali.shp is an ESRI polygon Shapefile ( $\left.{ }^{*} . \operatorname{shp}\right)$, which can be read by common Geoinformation Systems (GIS). A Shapefile stores the geometry and attributes of spatial features [19]. Attributes are held in a dBASE ${ }^{\circledR}$ format file. The dataset is projected in WGS 84/UTM zone 36S (EPSG: 32736$)$. The shapefile comes with a Layer file $\left({ }^{*} .1 y r\right)$ that provides an optional symbology for ESRI ArcGIS software packages, a Styled Layer Descriptor ( ${ }^{*}$.sld) that provides an optional symbology for other GIS tools, as well as a QGIS metadata file $\left({ }^{*}\right.$. qmd $)$.

\subsection{Data Structure}

The 2008-2009 and the 2015 information on the building stock, as well as the change information is stored in a single Shapefile. Table 7 shows the structure and coding of the attribute table.

Table 7. Attributes of the dataset (EO4Kigali.shp).

\begin{tabular}{|c|c|c|c|}
\hline Column Name & Content & Valid for 2008-2009 & Valid for 2015 \\
\hline Model & $\begin{array}{l}\text { Value "1" indicates that the object results from the splitting of a large } \\
\text { "Basic" building segment according to the LUT in Section 2.6. }\end{array}$ & $x$ & $x$ \\
\hline Change & $\begin{array}{l}\text { Indicates the type of change between } 2008-2009 \text { and } 2015 \text {. The value } \\
\text { ranges from } 1-6 \text { for } 2008-2009 \text {, and from } 1-5 \text { for } 2015 \text { (see Table } 3 \text { ). }\end{array}$ & $x$ & $x$ \\
\hline 2015_ty & $\begin{array}{l}\text { Indicates the building archetype by code for the year 2015. The value } \\
\text { ranges from 1-9 (0 in case a building that existed in 2008-2009 } \\
\text { was demolished). }\end{array}$ & & $x$ \\
\hline 2009_ty & $\begin{array}{l}\text { Indicates the building archetype by code for } 2008 / 2009 \text {. The value } \\
\text { ranges from 1-9 (0 in the case that a building was newly built } \\
\text { between } 2008 / 2009 \text { and 2015). }\end{array}$ & $x$ & \\
\hline 2015_name & Indicates the building archetype by its short name for the year 2015 . & & $\mathrm{X}$ \\
\hline 2009_name & Indicates the building archetype by its short name for the year 2009 . & $x$ & \\
\hline Height & $\begin{array}{l}\text { Corrected mean object height in } \mathrm{m} \text { (corresponds to the } \\
2015 \text { buildings). }\end{array}$ & & $x$ \\
\hline Shape_Leng & Total perimeter of the object in $\mathrm{m}$. & $x$ & $x$ \\
\hline Shape_Area & Total area of the object in $\mathrm{m}^{2}$. & $x$ & $x$ \\
\hline UID & Unique identifier (Integer) of an object feature. & $x$ & $x$ \\
\hline
\end{tabular}

\section{User Notes}

In this section, the authors give some recommendations for working with the dataset. The number and the geometries of a large part of the "Basic" buildings is the result of a modelling approach informed by the descriptive statistics derived for the sample of manually digitized building footprints. Therefore, the authors advise against reliance on the numbers of the "Basic" building class as more than estimates but to utilize the area statistics for more reliable statistical analyses. 
Structured Query Language (SQL) can be used to analyze the attributes of the dataset. The following list of exemplary SQL queries might help data users to retrieve additional results and become familiar with the dataset:

- Which buildings existed in 2015?

- $\quad$ SELECT FROM EO4Kigali.shp WHERE (F2015_ty > 0)

- Which buildings existed in 2008-2009?

- $\quad$ SELECT FROM EO4Kigali.shp WHERE (Change $=1$ OR Change $=3$ OR Change $=4$ OR Change $=6$ )

- Which/how many "Bungalow" buildings existed in 2015?

- $\quad$ SELECT FROM EO4Kigali.shp WHERE (F2015_ty = 3)

- For which buildings were no changes detected between 2008-2009 and 2015?

- $\quad$ SELECT FROM EO4Kigali.shp WHERE (Change = 1)

- Which/how many buildings were demolished between 2008-2009 and 2015?

- $\quad$ SELECT FROM EO4Kigali.shp WHERE (Change = 6)

- To include buildings that were rebuilt/renovated to a new building type:

- $\quad$ SELECT FROM EO4Kigali.shp WHERE (Change $=6$ OR Change $=4)$

- Which/how many were newly built/rebuilt between 2008-2009 and 2015?

- SELECT FROM EO4Kigali.shp WHERE (Change $=2$ OR Change $=3$ OR Change $=4$ OR Change $=5)$; (Remark: with Change $=3$ buildings are included that might only be renovated or slightly changed).

- Which/how many of object geometries of the "Basic" buildings were modelled and do therefore not represent the actual delineation to adjacent buildings?

- $\quad$ SELECT FROM EO4Kigali.shp WHERE (Model = 1)

Supplementary Materials: The following are available online at http://www.mdpi.com/2306-5729/4/3/105/s1, File1: Building archetypes description, File2: Illustrations of the dataset, File3: EO4Kigali.shp dataset with auxiliary files (see Section 3.4).

Author Contributions: Conceptualization, F.B.; methodology, F.B.; validation, F.B.; formal analysis, F.B., A.B., F.A., and P.d.A.; investigation, F.B. and J.B.; resources, F.B., A.P.M., and E.K.; data curation, F.B.; writing-original draft preparation, F.B.; writing-review and editing, all authors; visualization, F.B.; project administration, F.B.; funding acquisition, F.B. and S.M.

Funding: This research was supported by the German Ministry of Education and Research (Bundesministerium für Bildung und Forschung, BMBF) with the research project Rapid Planning, grant number 01LG1301K and the International Growth Centre (IGC), grant number VCU-VRWA-VXXXX-38418.

Acknowledgments: We acknowledge the support of student assistants Nina Gnann, Thomas Spieß, Johanna Kinkela, and Thimm Zwiener in the manual editing and of the support of Vianney Byiringiro in the collection of reference data.

Conflicts of Interest: The authors declare no conflicts of interest. The funders had no role in the design of the study; in the collection, analyses, or interpretation of data; in the writing of the manuscript; or in the decision to publish the results. 


\section{References}

1. Musakwa, W.; Niekerk, A.V. Earth observation for sustainable urban planning in developing countries: Needs, trends, and future directions. J. Plan. Lit. 2015, 30, 149-160. [CrossRef]

2. Bachofer, F.; Murray, S. Remote Sensing for Measuring Housing Supply in Kigali; C-38418-RWA-1; IGC: London, UK, 2018; p. 38.

3. NISR; MINECOFIN. Rwanda Fourth Population and Housing Census 2012; National Institute of Statistics of Rwanda (NISR, Rwanda), Ministry of Finance and Economic Planning (MINECOFIN, Rwanda): Kigali, Rwanda, 2015; p. 99.

4. Nduwayezu, G.; Sliuzas, R.; Kuffer, M. Modeling urban growth in Kigali city Rwanda. Rwanda J. $2017,1$. [CrossRef]

5. Shrijan, J.; Shrena, J.; Hrydhal, D.; Juvena, N.; Lissiana, L. Kigali City Master Plan Report; RWF1101_03; Surbana: Kigali City, Rwanda, 2013.

6. Gleyzes, M.A.; Perret, L.; Kubik, P. Pleiades System Architecture and Main Performances. In Proceedings of the ISPRS-International Archives of the Photogrammetry Remote Sensing and Spatial Information Sciences, Melbourne, Australia, 25 August-1 September 2012; pp. 537-542.

7. Ghassemian, H. A review of remote sensing image fusion methods. Inf. Fusion 2016, 32, 75-89. [CrossRef]

8. Sagashya, D.G. Launching the New Rwanda Basemap 1:50,000; Rwanda Natural Resources Authority-RNRA: ESRI GIS-day Kigali, Rwanda, 2014.

9. Blaschke, T. Object based image analysis for remote sensing. ISPRS J. Photogramm. Remote Sens. 2010, 65, 2-16. [CrossRef]

10. Baatz, M.; Schäpe, A. Multiresolution segmentation: An optimization approach for high quality multi-scale image segmentation. In Angewandte Geographische Informations-Verarbeitung, XII; Strobl, J., Blaschke, T., Griesbner, G., Eds.; Wichmann Verlag: Karlsruhe, Germany, 2000; pp. 12-23.

11. Ma, L.; Li, M.; Blaschke, T.; Ma, X.; Tiede, D.; Cheng, L.; Chen, Z.; Chen, D. Object-based change detection in urban areas: The effects of segmentation strategy, scale, and feature space on unsupervised methods. Remote Sens. 2016, 8, 761. [CrossRef]

12. Canny, J. A computational approach to edge detection. IEEE Trans. Pattern Anal. Mach. Intell. 1986, PAMI-8, 679-698. [CrossRef]

13. Bachofer, F.; Quénéhervé, G.; Zwiener, T.; Maerker, M.; Hochschild, V. Comparative analysis of edge detection techniques for SAR images. Eur. J. Remote Sens. 2016, 49, 205-224. [CrossRef]

14. OpenStreetMap. (C) OpenStreetMap Contributors. Available online: https://www.openstreetmap.org (accessed on 15 October 2014).

15. Gribov, A. Searching for a compressed polyline with a minimum number of vertices (discrete solution). In Graphics Recognition. Current Trends and Evolutions; Springer International Publishing: Cham, Switzerland, 2018; pp. 54-68.

16. Baker, W.L.; Cai, Y. The r.Le programs for multiscale analysis of landscape structure using the grass geographical information system. Landsc. Ecol. 1992, 7, 291-302. [CrossRef]

17. d'Angelo, P.; Kuschk, G. Dense multi-view stereo from satellite imagery, IGARSS 2012. In Proceedings of the IEEE, Munich, Germany, 22-27 July 2012; pp. 6944-6947.

18. Perko, R.; Raggam, H.; Gutjahr, K.H.; Schardt, M. Advanced DTM generation from very high resolution satellite stereo images. In Proceedings of the ISPRS Annals of Photogrammetry Remote Sensing and Spatial Information Sciences, Munich, Germany, 25-27 March 2015; Volume II-3/W4, pp. 165-172. [CrossRef]

19. ESRI. Esri Shapefile Technical Description; Environmental Systems Research Institute, Inc. (ESRI): Redlands, CA, USA, 1998.

(C) 2019 by the authors. Licensee MDPI, Basel, Switzerland. This article is an open access article distributed under the terms and conditions of the Creative Commons Attribution (CC BY) license (http://creativecommons.org/licenses/by/4.0/). 